\title{
Depth profile analysis of copper coating on steel using laser ablation inductively coupled plasma mass spectrometry
}

\author{
Aurora G. Coedo, $* a$ Teresa Dorado, ${ }^{a}$ Isabel Padilla $^{a}$ and Juan C. Fariñas ${ }^{b}$ \\ ${ }^{a}$ Centro Nacional de Investigaciones Metalúrgicas (CSIC), 28040 Madrid, Spain. \\ E-mail: coedo@cenim.csic.es \\ ${ }^{\boldsymbol{b}}$ Instituto de Cerámica y Vidrio (CSIC), Campus de Cantoblanco, 28049 Madrid, Spain. \\ E-mail:jcfarinas@icv.csic.es
}

Received 22nd March 2005, Accepted 10th May 2005

First published as an Advance Article on the web 9th June 2005

\begin{abstract}
A commercial highly focused (Gaussian) nanosecond UV (266 nm) Nd:YAG laser ablation system coupled to an inductively coupled plasma quadrupole mass spectrometer was examined as a tool for depth profile analysis of copper coating on steel. The studied samples were Standard Reference Materials 1361b and $1362 \mathrm{~b}$ from NIST, which consist of a set of eight coupons of an AISI 1010 cold rolled sheet steel substrate with a uniform coating of copper (certified copper coating thickness: 5.9, 12.3, 25.3, 40.6, 52.0, 77, 130, and $199 \mu \mathrm{m})$. Depth resolution was determined from the normalized depth profiles as a function of irradiance, which was varied by changing the laser pulse energy and the focusing conditions, as well as coating thickness. At lower irradiances, depth resolution values were higher for irradiances obtained by changing the laser pulse energy, whereas at higher irradiances this parameter was higher for irradiances obtained by changing the focusing conditions. At moderate irradiance levels, the results obtained were quite similar, and, in addition, the best depth resolution was attained in this irradiance range, which was obtained by using a moderate laser energy (about $2 \mathrm{~mJ}$ per pulse) and by focusing the laser beam below the sample surface (approximately $2000 \mu \mathrm{m}$ ). Depth resolution increased linearly with coating thickness. For the eight studied samples the ablation rate was approximately $1 \mu \mathrm{m}$ per pulse and the depth resolution values were between $0.8 \mu \mathrm{m}$ for the thinnest coating and $26 \mu \mathrm{m}$ for the thickest one.
\end{abstract}

\section{Introduction}

The highly increased demand for materials with treated surfaces as well as the increased requirements these materials have to meet with respect to steady quality have led to a considerable progress in the field of surface analysis technology. Layer deposition is a method often used to modify the surface of materials in order to improve hardness and resistance to corrosion. The physical and chemical properties of coatings mainly depend on coating mass or thickness, coating composition and the depth distribution of the coating elements. Therefore, precise qualitative and quantitative depth profile analysis is required to check the coating quality. Several techniques are suitable for determining the element composition of layered materials as a function of depth. Among the most widely used can be cited Auger electron spectroscopy, X-ray photoelectron spectroscopy, secondary ion mass spectrometry, secondary neutral mass spectrometry, electron probe microanalysis, glow discharge optical emission spectrometry, and glow discharge mass spectrometry. However, different limitations (restriction of sample shape or nature, poor lateral resolution, working under vacuum conditions, sampling on a scale of several $\mathrm{nm}$ to a few micrometers, necessity for complex matrix-related interference corrections, long time required for analysis, etc.) impede the universal application of one or other of these techniques.

Pulsed laser ablation (LA) has become a powerful tool for the direct sampling of solid materials. ${ }^{1-6}$ LA-based analytical techniques include: (i) laser-induced breakdown spectrometry (LIBS), also known as laser-induced plasma spectrometry (LIPS), in which the microplasma formed above the sample surface is directly analysed through optical emission spectrometry; (ii) LA time-of-flight mass spectrometry (LA-TOFMS), also known as laser ionization time-of-flight mass spectrometry (LI-TOF-MS), in which laser ablation is carried out in a vacuum and the ablated ions are detected directly through time-of-flight mass spectrometry; (iii) LA inductively coupled plasma atomic emission spectrometry (LA-ICP-AES), in which the ablated matter is carried in a gas stream to an ICP and detected through atomic (optical) emission spectrometry; and (iv) LA inductively coupled plasma mass spectrometry (LAICP-MS), in which the ablated matter is carried in a gas stream to an ICP and detected through mass spectrometry. The four techniques have been used for the determination of compositional depth profiles of layered materials.

LIBS has been applied successfully to depth profiling analysis of metal samples with different thin coatings (thicknesses from 0.02 to $8 \mu \mathrm{m}$ ): steel coated with a single layer of $\mathrm{Cr},{ }^{7} \mathrm{Sn},{ }^{7,8}$ $\mathrm{Zn},{ }^{9-13}$ and $\mathrm{Zn} / \mathrm{Ni} ;{ }^{7}$ brass coated with two layers of $\mathrm{Cu}$ and $\mathrm{Ni},{ }^{14}$ and with three layers of $\mathrm{Cu}, \mathrm{Ni}$ and $\mathrm{Cr} ;{ }^{11,15}$ nickel coated with a single layer of $\mathrm{Cr}^{8}$ and silicon coated with a single layer of $\mathrm{TiO}_{2}{ }^{16}$ and with a sandwich multilayer of $\mathrm{Cu}-\mathrm{Ag} .{ }^{17}$

LA-TOF-MS has been evaluated by García et al. ${ }^{13}$ for the depth profiling of a $\mathrm{Zn}$ coating on steel (coating thickness of approximately $10 \mu \mathrm{m}$ ). Margetic et al. ${ }^{17,18}$ have described the depth analysis of complex multilayered materials: iron coated with ten alternating TiN and TiAlN layers, each having a thickness of $280 \mathrm{~nm}$, and a silicon wafer coated with nine alternating $\mathrm{Cr}$ and Ni layers, each having a thickness of 56 and $57 \mathrm{~nm}$, respectively.

LA-ICP-AES has been used by Kanicky et al. ${ }^{19,20}$ to perform the depth profiling of a glass coated with a $300 \mathrm{~nm}$ thick Sn single layer, and a steel coated with three layers (a partially stabilized zirconia, a graded metal-ceramic zone and a NiCrAlY alloy) with a total coating thickness of $700 \mu \mathrm{m}$.

LA-ICP-MS has been examined by Bleiner et al. ${ }^{21}$ for the spatially resolved quantitative profiling of compositionally graded $\mathrm{Co}$ and $\mathrm{Mn}$ perovskite layers. Plotnikov et al..$^{22}$ and Bleiner et al. ${ }^{23}$ have performed depth profiling studies on steel and $\mathrm{WC} / \mathrm{Co}$ substrates coated with single layers of $\mathrm{TiC}$, TiN, 
$\mathrm{Ti}(\mathrm{C}, \mathrm{N})$ and $(\mathrm{Ti}, \mathrm{Al}) \mathrm{N}$ (coating thickness from 1.5 to $7 \mu \mathrm{m})$. Kanicky et al. ${ }^{24}$ have reported the dependence of depth profiling capabilities on the depth/diameter aspect ratio of the craters for steel coated with single layers of $\mathrm{ZrN}$, TiN and ZrTiN (thickness of $3 \mu \mathrm{m}$ ). Mank and Mason ${ }^{25,26}$ have fully discussed the feasibility of the technique for depth-resolved analysis of homogeneous silica-based glass samples and multilayered glass and metal materials (coating thickness from 5 to $200 \mu \mathrm{m})$.

The aim of the present work is to evaluate the feasibility of a LA-ICP-MS system for the depth profiling of steel coated with copper single layers of certified thicknesses by studying the dependence of depth resolution on irradiance and coating thickness.

\section{Experimental}

\section{Instrumentation}

Experiments were performed with a commercially available quadrupled (266 $\mathrm{nm})$ nanosecond $\mathrm{Nd}: Y A G$ laser with Q-switch (LSX-100, CETAC Technologies, Omaha, Nebraska, USA) coupled to an ICP quadrupole mass spectrometer (ELAN 6000, PerkinElmer SCIEX, Thornhill, Ontario, Canada). The operating conditions of both the laser ablation and the ICP-MS instruments are listed in Table 1. Instrument conditions were optimized for best time-resolved data acquisition. The laser pulse energy was measured with a laser power energy meter (EM 400, Molectron Detector, Inc., USA). The depth and diameter of the craters were measured by optical microscopy, and their morphology was observed by scanning electron microscopy, SEM (DSM 400, Zeiss, Germany).

\section{Samples}

Standard Reference Materials 1361b and 1362b (coating thickness standards) from NIST (National Institute of Standards and Technology) has been used. These samples consist of a preconfigured set of eight coupons certified for total coating thickness. Each coupon consists of an American Iron and Steel

Table 1 LA -ICP-MS operating conditions

\begin{tabular}{|c|c|}
\hline Parameter & Value \\
\hline \multicolumn{2}{|l|}{ LA (CETAC, LSX-100) } \\
\hline Laser type & Nd:YAG pulsed \\
\hline Laser mode & Q-switched \\
\hline Beam profile & $>95 \%$ fit to Gaussian \\
\hline Beam diameter & $1.0 \mathrm{~mm}$ \\
\hline Wavelength & $266 \mathrm{~nm}$ (ultraviolet) \\
\hline Pulse width & $8 \mathrm{~ns}$ \\
\hline Transverse mode & $\mathrm{TEM}_{00}$ single mode \\
\hline Pulse energy output & $1-20$ arbitrary units \\
\hline Pulse repetition rate & $1-20 \mathrm{~Hz}$ \\
\hline $\begin{array}{l}\text { Transport from ablation } \\
\text { cell to MS }\end{array}$ & $\begin{array}{l}\text { Tygon tube } \\
(60 \mathrm{~cm} \text { in length, } 5 \mathrm{~mm} \text { id })\end{array}$ \\
\hline \multicolumn{2}{|c|}{ ICP-MS (PerkinElmer SCIEX, ELAN 6000) } \\
\hline $\mathrm{Rf}$ forward power & $1100 \mathrm{~W}$ \\
\hline Ar plasma flow rate & $141 \mathrm{~min}^{-1}$ \\
\hline Ar carrier flow rate & $0.651 \mathrm{~min}^{-1}$ \\
\hline ICP frequency & 40.86 MHz (free-running) \\
\hline Detector & Dual mode \\
\hline Analytes & $\mathrm{Cu}, \mathrm{Fe}$ \\
\hline Dwell time & $10 \mathrm{~ms}$ \\
\hline Sweeps/reading & 3 \\
\hline Readings/replicate & $\begin{array}{l}\text { As many as provide enough replicate } \\
\text { time to reach the substrate }\end{array}$ \\
\hline Replicates & 1 \\
\hline
\end{tabular}

Table 2 Certified copper coating thickness values

\begin{tabular}{lccl}
\hline Coupon & $\begin{array}{l}\text { Nominal coating } \\
\text { thickness } / \mu \mathrm{m}\end{array}$ & $\begin{array}{l}\text { Certified coating } \\
\text { thickness } / \mu \mathrm{m}\end{array}$ & $\begin{array}{l}\text { Standard } \\
\text { uncertainty } / \mu \mathrm{m}\end{array}$ \\
\hline $\mathrm{A}$ & 6 & $5.9 \pm 0.1$ & 0.09 \\
$\mathrm{~B}$ & 12 & $12.3 \pm 0.2$ & 0.18 \\
$\mathrm{C}$ & 25 & $25.3 \pm 0.4$ & 0.30 \\
$\mathrm{D}$ & 40 & $40.6 \pm 0.6$ & 0.25 \\
$\mathrm{E}$ & 48 & $52.0 \pm 0.8$ & 0.40 \\
$\mathrm{~F}$ & 80 & $77 \pm 1.2$ & 0.30 \\
$\mathrm{G}$ & 140 & $130 \pm 2.0$ & 1.09 \\
$\mathrm{H}$ & 205 & $199 \pm 3$ & 0.55 \\
\hline
\end{tabular}

Institute (AISI) 1010 cold rolled sheet steel substrate with a uniform coating of copper, then overplated with a thin protective layer of chromium. Certified copper coating thickness values and standard uncertainties (which are to be taken as an indication of thickness variation across the surface of the coupon) are listed in Table 2. Prior to analysis, the samples were cleaned with methanol, rinsed with deionized water and dried.

\section{Procedure}

In our approach, the depth characterization of the samples was performed by continuously and simultaneously monitoring the $\mathrm{Cu}$ and $\mathrm{Fe}$ analyte signals from multiple laser pulses fired at a fixed location. The studied range of laser pulse energy varied from a minimum of $0.4 \mathrm{~mJ}$ pulse ${ }^{-1}$ to a maximum of $3.3 \mathrm{~mJ}$ pulse $^{-1}$ (corresponding to the interval 1-20 arbitrary units). Focal conditions were varied by shifting the stage (and consequently the ablation cell and the sample) in the $z$-axis (vertical direction) relative to the focusing lens. The working distance (WD) was defined as the difference between the lens-to-sample distance and the focal length of the lens. For instance, a WD of zero denotes that the surface of the sample was placed at the lens' focal distance (i.e., the laser beam was focused at the sample surface). The negative values (e.g. WD $=-1000$ ) indicate that the lens focal point was placed $1000 \mu \mathrm{m}$ above the sample surface (i.e., the laser beam was focused at a position above the sample surface, or, in others words, in argon), while positive values (e.g., $\mathrm{WD}=+1000)$ mean that the beam is focused $1000 \mu \mathrm{m}$ within the material (i.e., the laser beam was focused at a position below the sample surface). The error bars in the plots represent standard deviation values based on 5 replicates.

\section{Results and discussion}

\section{General behaviour of the LA-ICP-MS in-depth profiles}

When a laser is fired repetitively over a single position of the surface of a coated sample containing an element in the coating and another element in the substrate, the monitoring of the ICP-MS ion intensities of all elements as a function of time (or number of laser pulses) provides the in-depth profile of the coated sample. Fig. 1 shows a typical in-depth profile obtained by ablating the $80 \mu \mathrm{m}$ nominal thickness copper coating on a steel sample with "soft conditions": an energy of $1.5 \mathrm{~mJ}$ pulse $^{-1}$, a pulse repetition rate of $2 \mathrm{~Hz}$ and defocusing (laser focused $2000 \mu \mathrm{m}$ within the sample, i.e., $\mathrm{WD}=+2000 \mu \mathrm{m})$. Some general trends could be observed in this figure for the signals of $\mathrm{Cr}, \mathrm{Cu}$ and $\mathrm{Fe}$ (in this preliminary test, the signal of $\mathrm{Cr}$ from the thin protective layer, less than $1 \mu \mathrm{m}$ thickness, was also monitored): firstly, there is a very narrow peak (i.e., a steep rise and drop of the $\mathrm{Cr}$ signal) which reaches the zero after a few seconds, and which corresponds to the ablation of the very thin protective layer of $\mathrm{Cr}$. After this, exactly at the time corresponding to the maximum of this peak (i.e., when the 


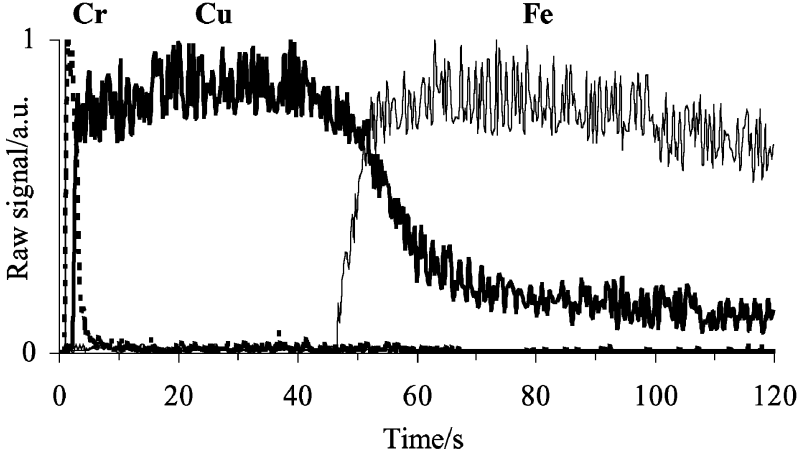

Fig. 1 Raw in-depth profile obtained by ablating the $80 \mu \mathrm{m}$ nominal thickness copper coating on steel sample. Laser pulse energy: $1.5 \mathrm{~mJ}$ pulse repetition rate: $2 \mathrm{~Hz}$; and WD: $+2000 \mu \mathrm{m}$.

thin $\mathrm{Cr}$ layer has been drilled), an abrupt rise in the $\mathrm{Cu}$ signal appears, followed by a steady-state during $c a .45$ s corresponding to the ablation through the $\mathrm{Cu}$ coating layer; after this time (i.e., after 90 pulses) the signal slowly drops, although it does not reach zero. Finally, when the signal of $\mathrm{Cu}$ starts to drop, there is a steep rise of the Fe signal, indicating that the steel substrate has been reached, followed by a plateau. As can be seen in the figure, the $\mathrm{Cr}$ protective layer $/ \mathrm{Cu}$ coating interface is properly resolved. However, the $\mathrm{Cu}$ coating/steel substrate interface is not well-resolved, because the ICP-MS response for $\mathrm{Cu}$ decreased at a much slower rate than the increase for $\mathrm{Fe}$ signal: by the time ( $c a .7-8 \mathrm{~s}$ or $14-16$ pulses) that the Fe signal increases from 0 to the steady-state (i.e., a 100\%), the $\mathrm{Cu}$ signal shows a decrease lower than $20 \%$. Since a very thin, welldefined coating/substrate interface exists in the sample, and no diffusion of elements from one layer to another takes place, it can be stated that the measured interface is broader than the original in-depth distribution of composition, that is, the shape of the resulting profile is really a distorted image of the true coating/substrate interface. Similar behavior has already been described by other authors. ${ }^{26,27}$

In order to complete this study, the same experiment was performed by taking the same sample and ablating from the other side (i.e., from the steel substrate) across the steel substrate $/ \mathrm{Cu}$ coating and $\mathrm{Cu}$ coating $/ \mathrm{Cr}$ protective layer interfaces. To carry out this test, the steel substrate, which was too coarse $(c a .2000 \mu \mathrm{m})$, was thinned to about $90 \mu \mathrm{m}$ (as measured by optical microscopy) by grinding. The obtained in-depth profile is shown in Fig. 2. As can be seen, identical trends as compared with Fig. 1 are attained, with a very gradual decay of the Fe signal and a soaring $\mathrm{Cu}$ signal at the steel substrate $/ \mathrm{Cu}$ coating interface, and a slow drop in the $\mathrm{Cu}$ signal and a narrow peak of $\mathrm{Cr}$ at the $\mathrm{Cu}$ coating/Cr protective layer interface.

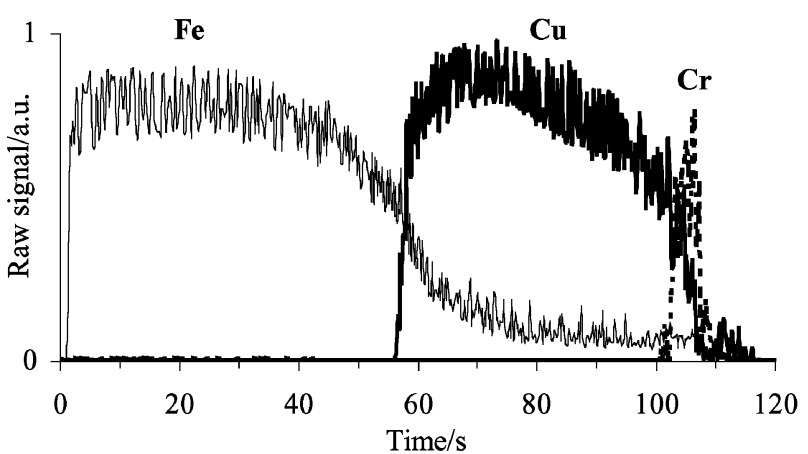

Fig. 2 Raw in-depth profile obtained by ablating, from the stee substrate (thinned to about $90 \mu \mathrm{m}$ ), the $80 \mu \mathrm{m}$ nominal thicknes copper coating on steel sample. Laser pulse energy: $1.5 \mathrm{~mJ}$; pulse repetition rate: $2 \mathrm{~Hz}$; and WD: $+2000 \mu \mathrm{m}$.
The ablation rate (ablated depth per second or per laser pulse) in the $\mathrm{Cu}$ and steel layers can be calculated from Figs. 1 and 2 by considering the drill time (i.e., the time interval between the rise of the signals of the coating element and the substrate element) ${ }^{22}$ and the thicknesses of the $\mathrm{Cu}$ coating (77 $\mu \mathrm{m}$ ) and of the thinned steel substrate (about $90 \mu \mathrm{m}$ ). The drill time values obtained are about $43 \mathrm{~s}$ (Fig. 1) and $57 \mathrm{~s}$ (Fig. 2). Consequently, the values calculated for the ablation rate are approximately $1.8 \mu \mathrm{m} \mathrm{s}^{-1}$ (or $0.9 \mu \mathrm{m}$ pulse ${ }^{-1}$ ) for the $\mathrm{Cu}$ layer and $1.6 \mu \mathrm{m} \mathrm{s}^{-1}$ (or $0.8 \mu \mathrm{m}$ pulse ${ }^{-1}$ ) for the steel layer. Thus, the laser ablates approximately 1.1 times faster in copper than in steel. From the above results, it can be inferred that changes in the physical or chemical properties of the coating and substrate, and changes in the geometry of the crater, are not responsible for the broadening of the interface. On the other hand, for the reasons explained above, this behavior may not be assigned to chemical diffusion across the interface between the two layers. Moreover, when laser is switched off in our LAICP-MS system, the signal decreased to the background level within about $5 \mathrm{~s}$ (equivalent to 5-10 pulses for a repetition rate of 1-2 Hz), suggesting that the throughput of sample from ablation cell to plasma is very rapid. Because of this, mixing of ablated particles during transport from the ablation cell to the ICP-MS cannot be responsible for the observed trend.

Taking all this into account, it can be stated that the depth profile trend is mainly determined by the ablation process. In nanosecond UV pulsed laser ablation of metals, the predominant thermal effects associated with the ablation process create a relatively large molten layer. The sample is removed both in vapor and liquid phases, since the vaporization process creates a high pressure that expels the liquid (melt ejection). This pressure results from the recoil of the ablated material and the expanding cloud of vapor and plasma determining the material transport out of the crater. This re-solidified molten material (droplets) can be perfectly observed in Fig. 3, where a crater obtained by ablation of the steel substrate with 2 laser pulses at an energy of $3.3 \mathrm{~mJ}$ pulse ${ }^{-1}$ and $\mathrm{WD}=+1000 \mu \mathrm{m}$ is shown. In addition, at the bottom of the crater the vapor pressure of the evaporating material acts as a piston, forcing molten material in a radial direction. As a result, the walls of the crater are covered with a thin molten film formed through melt expulsion by the vapor pressure, corresponding to the material which has not been completely expelled. ${ }^{28-31}$ Consequently, modification and mixing of different depth layers along the crater walls between shallow and deep levels occurs. We think, in accordance with other authors, ${ }^{17,25,26}$ that the indepth profile behaviour is very probably due to this ablation process. Moreover, given that the Gaussian laser beam produces a cone-shaped crater, subsequent pulses will ablate material from the crater walls as well as from the crater

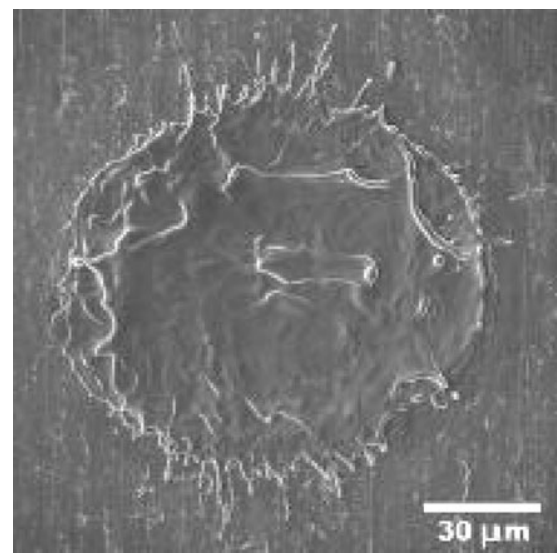

Fig. 3 SEM image of a crater obtained by ablation of an AISI 1010 cold rolled sheet steel sample. Number of laser pulses: 2; laser pulse energy: $3.3 \mathrm{~mJ}$; and WD: $+1000 \mu \mathrm{m}$. 


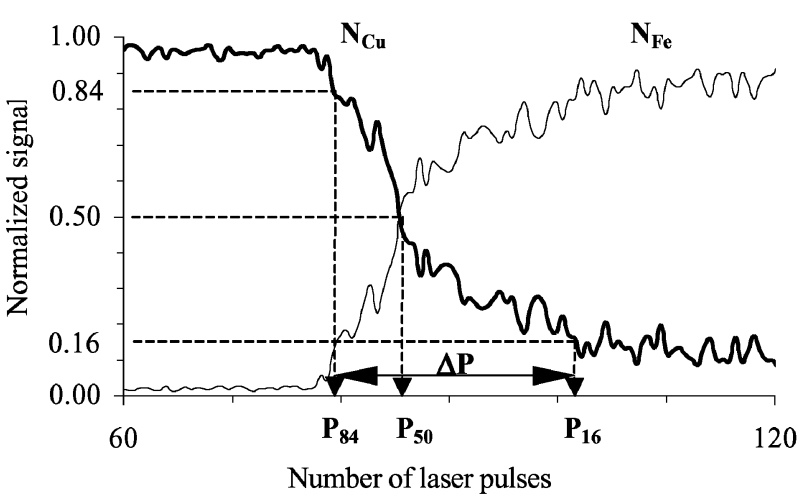

Fig. 4 Normalized in-depth profile, in the region of the coating/ substrate interface, obtained by ablating the $80 \mu \mathrm{m}$ nominal thickness copper coating on steel sample. The parameters $\left(P_{84}, P_{50}, P_{16}\right.$ and $\left.\Delta P\right)$ involved in the determination of $\Delta z$ are shown. Laser pulse energy: $1.5 \mathrm{~mJ}$; pulse repetition rate: $2 \mathrm{~Hz}$; and WD: $+2000 \mu \mathrm{m}$.

bottom, so that around the coating/substrate interface the ablation of the $\mathrm{Cu}$ coating will continue even after penetration of the beam into the steel substrate. ${ }^{12,27,32}$

The broadening at the interface depends on a number of different phenomena that are usually categorized into sample characteristics, instrumental factors and beam/sample interactions (laser wavelength, pulse duration, beam shape, irradiance, etc.). The way of quantifying the broadening process is by means of the so-called depth resolution $(\Delta z)$. The basic concepts, from a general point of view, relating to definition, meaning and evaluation of depth resolution can be consulted in a paper by Hofmann. ${ }^{33}$ The procedure for the determination of depth resolution, followed in the present work, has been explained by Mateo et al. ${ }^{14}$ The $\Delta z$ value is calculated from the depth profile plot of normalized signals $\left[N_{\mathrm{Cu}}=I_{\mathrm{Cu}}\left(I_{\mathrm{Cu}}+\right.\right.$ $\left.I_{\mathrm{Fe}}\right)^{-1}$ and $N_{\mathrm{Fe}}=I_{\mathrm{Fe}}\left(I_{\mathrm{Cu}}+I_{\mathrm{Fe}}\right)^{-1}$, where $I_{\mathrm{Cu}}$ and $I_{\mathrm{Fe}}$ are the raw ion intensity] against the number of laser pulses. Hereafter, the $\mathrm{Cr}$ protective layer will not be considered, because its thickness is unknown, but very low $(<1 \mu \mathrm{m})$. To determine $\Delta z$ it is necessary to estimate firstly the average ablation rate (AAR) from the thickness of the coating $(D)$ and the number of pulses required to reach the coating/substrate interface $\left(P_{50}\right), \mathrm{P}_{50}$ being the number of laser pulses corresponding to a value of normalized intensity 0.50 (that is, $50 \%$ of the full signal):

$$
\operatorname{AAR}\left(\mu \mathrm{m} \text { pulse }^{-1}\right)=D(\mu \mathrm{m})\left(P_{50}\right)^{-1} \text { (pulses) }
$$

The $\Delta z$ is then obtained from the following equation:

$$
\Delta z(\mu \mathrm{m})=\Delta P(\text { pulses}) \text { AAR }\left(\mu \mathrm{m} \text { pulse }^{-1}\right)
$$

where $\Delta P$ is the difference in the number of laser pulses necessary to reach $84 \%\left(P_{84}\right)$ and $16 \%\left(P_{16}\right)$ of the normalized signal intensity, that is, $\Delta P=P_{16}-P_{84}$. The parameters involved in the determination of $\Delta z$ are illustrated in Fig. 4, where the normalized profile corresponding to Fig. 1 is plotted. Eqn. (2) predicts that the best depth resolution (i.e., the lowest $\Delta z)$ is obtained from experimental conditions in which AAR and $\Delta P$ are lowest. Consequently, the two factors (AAR and $\Delta P$ ) must be taken into account to predict the behaviour of $\Delta z$.

By maintaining the laser source and sample constant, the $\Delta z$ depends on the laser fluence $(F)$ or on the laser irradiance $(I)$. The fluence (and also the irradiance, since the pulse width has a fixed value for the laser system) depends only on the pulse energy and on the diameter of the crater. Hence, in order to obtain the best depth resolution, the variation of $\Delta z$ with the pulse energy and the crater diameter (which has been varied by changing the focalization, i.e., the WD) has been studied by

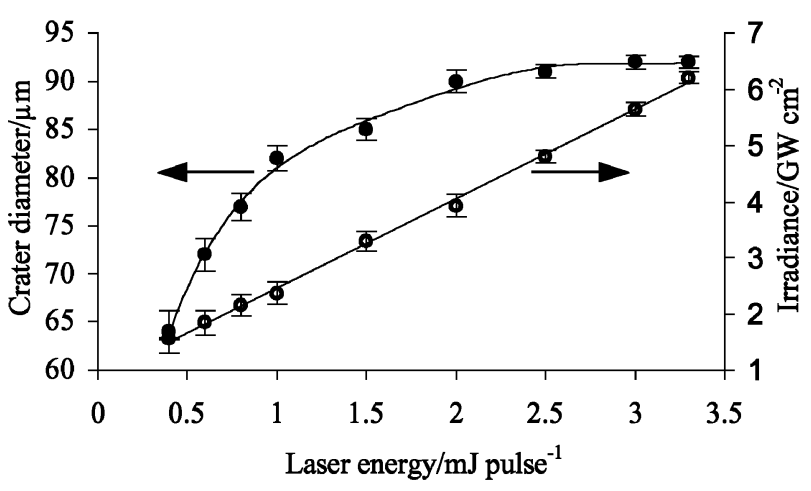

Fig. 5 Influence of laser pulse energy on crater diameter and irradiance. Sample: $205 \mu \mathrm{m}$ nominal thickness copper coating on steel; number of laser pulses: 100; pulse repetition rate: $1 \mathrm{~Hz}$; and WD: $+2000 \mu \mathrm{m}$.

performing two independent experiments, maintaining constant one of the variables at any time. In addition, taking into account eqn. (1), the influence of coating thickness $(D)$ on depth resolution has also been investigated.

\section{Influence of laser pulse energy on depth resolution}

The influence of laser energy on the crater's geometrical characteristics (width and depth) was tested in the range from 0.4 to $3.3 \mathrm{~mJ}$ per pulse for the $205 \mu \mathrm{m}$ nominal thickness copper coating on steel sample. This thickest coated sample was chosen in order to ablate only through the copper coating layer. For each laser energy value, the crater diameter and depth were measured after 100 pulses by working at WD = $+2000 \mu \mathrm{m}$ with the minimum pulse repetition rate $(1 \mathrm{~Hz})$. The influence of laser pulse energy on crater diameter and, consequently, on irradiance is presented in Fig. 5. The crater diameter shows a non-linear increase from 64 to $90 \mu \mathrm{m}$ with pulse energy (between 0.4 and $2 \mathrm{~mJ}$ per pulse), reaching a plateau at a pulse energy of $2 \mathrm{~mJ}$. On the contrary, irradiance varies linearly from 1.5 to $6.2 \mathrm{GW} \mathrm{cm}^{-2}$. Fig. 6 illustrates the dependence of width and depth of the crater on the number of laser pulses for a pulse energy of $2 \mathrm{~mJ}\left(I=3.9 \mathrm{GW} \mathrm{cm}^{-2}\right)$. The diameter at the top of the crater remains nearly constant, whereas the crater depth increases linearly with the number of laser pulses. An ablation rate of approximately $1 \mu \mathrm{m}$ per pulse is obtained from the slope of the linear fit.

From the data in Fig. 5, the ablation threshold fluence $\left(F_{\mathrm{th}}\right)$, which is defined as the fluence value above which the sample is ablated, can be determined. ${ }^{34-37}$ For a Gaussian beam profile, as the laser fluence in front of the sample surface depends linearly on the incident laser pulse energy (see Fig. 5), the $F_{\text {th }}$

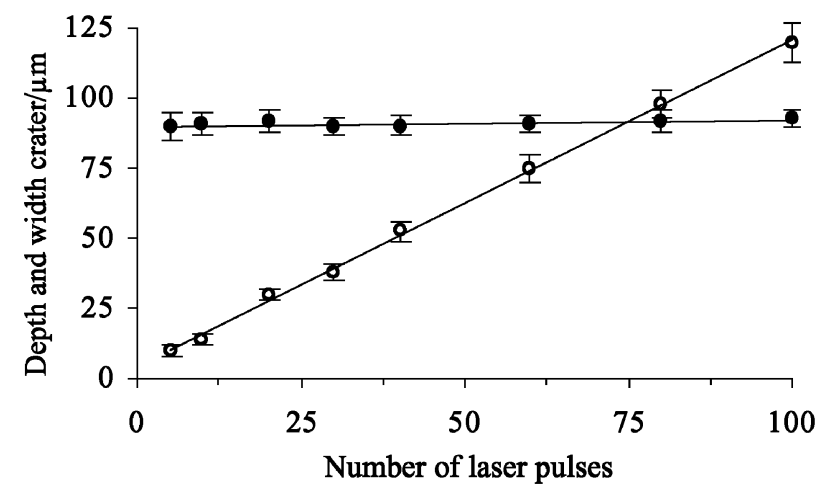

Fig. 6 Influence of number of laser pulses on depth (open symbols) and width (filled symbols) of the crater. Sample: $205 \mu \mathrm{m}$ nominal thickness copper coating on steel; laser pulse energy: $2 \mathrm{~mJ}$; pulse repetition rate: $1 \mathrm{~Hz}$; and $\mathrm{WD}:+2000 \mu \mathrm{m}$. 


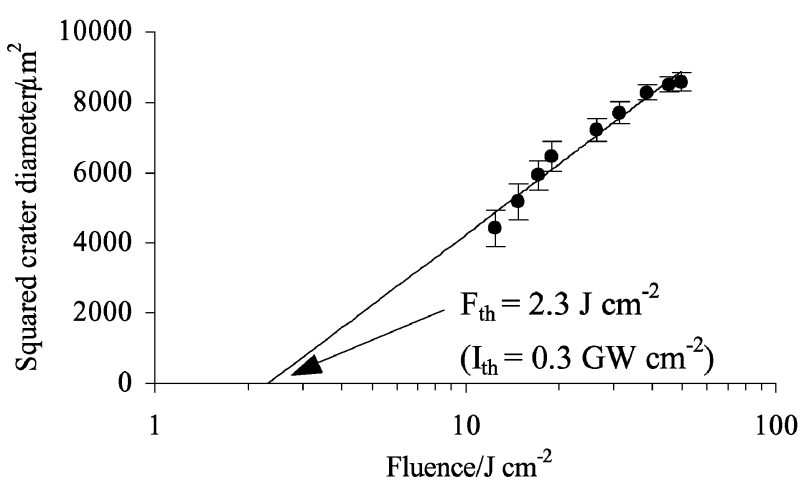

Fig. 7 Plot of squared crater diameters as a function of the logarithm of the applied laser fluence for the determination of the ablation threshold fluence (and irradiance). Sample: $205 \mu \mathrm{m}$ nominal thickness copper coating on steel; number of laser pulses: 100; pulse repetition rate: $1 \mathrm{~Hz}$; and WD: $+2000 \mu \mathrm{m}$.

can be determined by linearly fitting the square of the diameter of the crater versus the logarithm of the pulse fluence and extrapolating it to zero. ${ }^{37}$ The intersection point with the fluence axis determines the $F_{\text {th }}$ of the material. This determination can be performed by either single-pulse ablation ${ }^{36}$ or multiple-pulse ablation. ${ }^{34,35,37,38}$ In our case, as the copper coating is over-plated with a thin protective layer of chromium, the determination of $F_{\text {th }}$ cannot be performed by single-pulse ablation. Because of this, $F_{\text {th }}$ was determined (Fig. 7) from the crater diameter and laser pulse energy values depicted in Fig. 5, which were attained, as described above, after 100 laser pulses, i.e., by multiple-pulse ablation. The $F_{\text {th }}$ obtained from Fig. 7 is $2.3 \mathrm{~J} \mathrm{~cm}^{-2}$ (equivalent to an ablation threshold irradiance, $I_{\mathrm{th}}$, of $0.3 \mathrm{GW} \mathrm{cm} \mathrm{cm}^{-2}$ ). This $F_{\text {th }}$ value should correspond mainly to the ablation threshold of copper, but also, in a small proportion, to the ablation threshold of chromium (from the protective layer). This is consistent with the theoretical $F_{\text {th }}$ values calculated by Cabalín et al. ${ }^{39}$ for copper $\left(3.28 \mathrm{~J} \mathrm{~cm}^{-2}\right)$ and chromium $\left(1.67 \mathrm{~J} \mathrm{~cm}^{-2}\right)$.

From the above results, the study of the influence of laser pulse energy on the depth resolution has been performed for the $40 \mu \mathrm{m}$ nominal thickness copper coating on steel sample. Laser energy values of $0.4,1,2$ and $3.3 \mathrm{~mJ}_{\text {pulse }}^{-1}$ (irradiances ranging from 1.5 to $6.2 \mathrm{GW} \mathrm{cm}^{-2}$ ) have been evaluated,

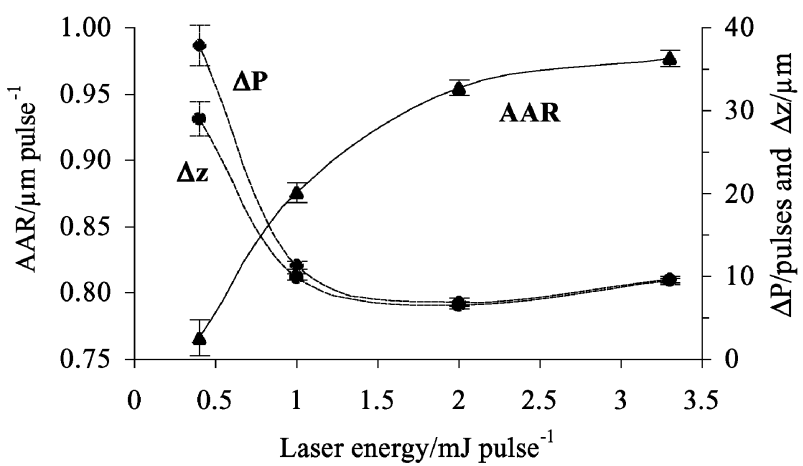

Fig. 8 Influence of laser pulse energy on AAR, $\Delta P$ and $\Delta z$. Sample: $40 \mu \mathrm{m}$ nominal thickness copper coating on steel; pulse repetition rate: $1 \mathrm{~Hz}$; and WD: $+2000 \mu \mathrm{m}$.

maintaining constant the defocusing of the laser beam (WD = $+2000 \mu \mathrm{m})$. The AAR, $\Delta P$ and $\Delta z$ values were calculated for each laser pulse energy from the depth profiles of normalized signals by using the eqns. (1) and (2), and are depicted in Fig. 8. The in-depth profiles (for both raw and normalized signals) obtained by applying the four laser pulse energy values are shown in Fig. 9.

As can be seen in Fig. 8, the AAR values increase slightly (from 0.77 to $0.95 \mu \mathrm{m}$ pulse ${ }^{-1}$, i.e., $0.18 \mu \mathrm{m}_{\text {pulse }}{ }^{-1}$ ) when the laser energy increases from 0.4 to $2 \mathrm{~mJ}_{\text {pulse }}^{-1}$, reaching a plateau at $2 \mathrm{~mJ}$. The steady-state reached at $2 \mathrm{~mJ}$ (irradiance of $3.9 \mathrm{GW} \mathrm{cm}^{-2}$ ) is probably due to the plasma shielding, i.e., the efficient attenuation of the incident laser beam by absorption and/or reflection of the laser-induced plasma that can occur at higher irradiances, which reduces the amount of laser energy that reaches the sample surface. ${ }^{40,41}$ The higher relative standard deviation (RSD) value (4\%) attained for the lowest laser energy is due to the uncertainty in the determination of the crossing point of the two normalized depth profiles of both $\mathrm{Cu}$ and Fe elements $\left(P_{50}\right)$, as can be seen in Fig. 9.

On the contrary, $\Delta P$ values decrease greatly (from 38 to 7 pulses, i.e., by a factor of 5.5), when the laser pulse energy increases from 0.4 to $2 \mathrm{~mJ}$ pulse ${ }^{-1}$. Between 2 and $3.3 \mathrm{~mJ}$ pulse $^{-1}$, the variation of $\Delta P$ is very low (only about 3 pulses). The high value of $\Delta P$, and its high RSD value (13\%), obtained for the lowest laser energy can be explained by the behaviour of
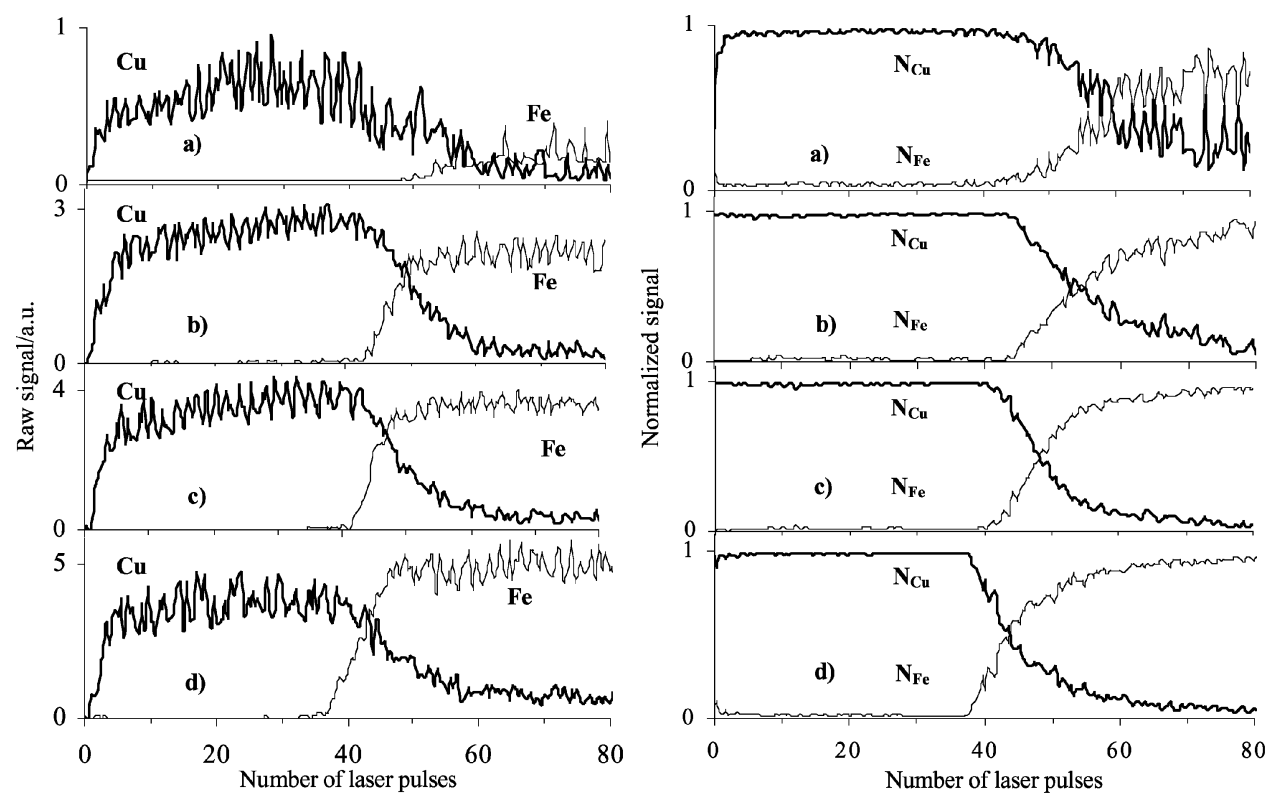

Fig. 9 Raw (left) and normalized (right) in-depth profiles obtained by ablating the $40 \mu \mathrm{m}$ nominal thickness copper coating on steel sample at different laser pulse energies: (a) $0.4 \mathrm{~mJ}$; (b) $1 \mathrm{~mJ}$; (c) $2 \mathrm{~mJ}$; and (d) $3.3 \mathrm{~mJ}$. Pulse repetition rate: $1 \mathrm{~Hz}$; and WD: $+2000 \mu \mathrm{m}$. 
both $\mathrm{Cu}$ and $\mathrm{Fe}$ ICP-MS signals in the depth profiles shown in Fig. 9. As can be seen in raw depth profiles at laser energy values higher than $0.4 \mathrm{~mJ}$ pulse ${ }^{-1}$, a steep rise of the $\mathrm{Cu}$ signal appears, followed by a steady-state. At around 40 pulses (equivalent to a depth of approximately $40 \mu \mathrm{m}$, taking into account, from Fig. 8, the corresponding AAR values, or, in other words, when the coating/substrate interface is reached), the $\mathrm{Cu}$ signal starts to decay from the same point at which the Fe signal rises. The raw depth profile at $0.4 \mathrm{~mJ}$ pulse ${ }^{-1}$ is quite different. The $\mathrm{Cu}$ signal rises slowly, reaches a maximum at about 25 pulses and, without a steady-state, drops very slowly. By considering an AAR of $0.77 \mu \mathrm{m}$ pulse ${ }^{-1}$ (Fig. 8), the very gradual decay of the $\mathrm{Cu}$ signal starts at a depth of $c a .20 \mu \mathrm{m}$, that is, when only the first half of the coating has been drilled. However, the rise of the $\mathrm{Fe}$ signal starts at about 50 pulses (i.e., at a depth of $c a .39 \mu \mathrm{m}$ ), showing that the steel substrate has been reached. Consequently, it can be stated that the behaviour of the $\mathrm{Cu}$ depth profile at the lowest laser pulse energy is not due to the presence of this metal as a coating, but to the ablation process itself and to the crater development. At a pulse energy of $0.4 \mathrm{~mJ}$ (equivalent to a fluence of $12.4 \mathrm{~J} \mathrm{~cm}^{-2}$ ), that is, at a fluence five times higher than the $F_{\text {th }}$, the ablation effectively occurs. However, due to the use of the highly focussed (Gaussian) beam, the ablation threshold is probably not reached outside the centre of the beam, and the sample absorbs the incident energy, but is not ablated. As a result, on the one hand the crater diameter at the surface is smaller than that achieved at higher pulse energies, as can be observed in Fig. 5, and on the other the crater significantly narrows with depth, giving rise to a crater with most irregular inside shape. Therefore, it is not possible to maintain uniform crater geometry with depth. Due to this poor ablation efficiency with depth, there is a large reduction in the amount of ablated material per pulse (and so a decrease of the intensities of both $\mathrm{Cu}$ and $\mathrm{Fe}$, and a poorer reproducibility), the $\mathrm{Cu}$ signal drops before reaching the coating/substrate interface, and the $\mathrm{Cu}$ coating, and mainly the steel substrate, are not successfully ablated. The very gradual drop of the $\mathrm{Cu}$ signal and the very gradual rise of the $\mathrm{Fe}$ signal, on the one hand, and the much higher uncertainty of the signals, on the other, are responsible for the higher $\Delta P$ and RSD values, respectively, obtained. Therefore, working with low-energy laser pulses is clearly unsuitable for depth analysis.

The behaviour of $\Delta z$ is quite similar to that of $\Delta P$. The highest $\Delta z$ value $(29 \mu \mathrm{m})$, with the highest RSD value $(14 \%)$, is attained for a laser pulse energy of $0.4 \mathrm{~mJ}$. The deterioration of depth resolution at the lowest energy is explained by the poor ablation efficiency, as mentioned above for $\Delta P$. Consequently, it can be concluded that the broadening of signals at coating/ substrate interface (i.e., $\Delta P$ ) is the more important factor influencing the depth resolution when the laser pulse energy is varied. The best depth resolution $(\Delta z=6.5 \mu \mathrm{m})$, with the lowest RSD value $(7 \%)$, has been obtained for a pulse energy of $2 \mathrm{~mJ}$ (i.e., an irradiance value of $3.93 \mathrm{GW} \mathrm{cm}^{-2}$, equivalent to about 13 times the ablation threshold irradiance). This pulse energy was used for all further experiments.

\section{Influence of focalization on depth resolution}

The effect of focalization on the crater width and, consequently, on the irradiance was studied by changing the WD from $-10000 \mu \mathrm{m}$ to $+10000 \mu \mathrm{m}$ for the $205 \mu \mathrm{m}$ nominal thickness copper coating on steel sample. This thickest coated sample was selected for the reason explained in the study of the influence of laser pulse energy. For each WD value, the crater diameter was measured after 100 pulses, by working at a laser energy of $2 \mathrm{~mJ}$ pulse ${ }^{-1}$ with the minimum pulse repetition rate $(1 \mathrm{~Hz})$. The influence of WD on crater diameter and on irradiance is presented in Fig. 10. As expected, the smallest crater $(45 \mu \mathrm{m}$ in diameter) and the highest irradiance (15.7 GW $\mathrm{cm}^{-2}$ ) are attained at the focal point, i.e., at WD $=0 \mu \mathrm{m}$. At focal conditions other than WD $=0 \mu \mathrm{m}$ (positive or negative), the higher the defocusing, the greater the crater diameter and the lower the irradiance. Irradiance decreases sharply from $15.7 \mathrm{GW} \mathrm{cm}^{-2}$ at $\mathrm{WD}=0 \mu \mathrm{m}$ to $2 \mathrm{GW} \mathrm{cm}^{-2}$ at $\mathrm{WD}=-2000$ $\mu \mathrm{m}$ and to $3.9 \mathrm{GW} \mathrm{cm}^{-2}$ at $\mathrm{WD}=+2000 \mu \mathrm{m}$. For $\mathrm{WD}$ values higher than $2000 \mu \mathrm{m}$ (positive or negative), the decrease of the irradiance is very slow. As can be observed, the curves of both irradiance and crater diameter are not symmetrical with respect to $\mathrm{WD}=0 \mu \mathrm{m}$. For a given absolute value of $\mathrm{WD}$, the irradiance corresponding to the negative value of WD is lower and the crater diameter is greater than that corresponding to a positive value of WD. A possible explanation to account for this result is that when the laser is focused above the sample surface (WD $<0 \mu \mathrm{m}$ ), the laser photons can ionize the argon (from the carrier gas of the ablation cell) at the focal point, forming a secondary plasma which can shield the sample from the laser, thus diminishing the amount of laser energy that reaches the sample surface. ${ }^{42}$

As reported in the study of the influence of laser pulse energy on depth resolution, working with low irradiances (1.5 GW $\mathrm{cm}^{-2}$ or less) is clearly unsuitable for depth analysis. On the other hand, higher irradiances $\left(>6.2 \mathrm{GW} \mathrm{cm}^{-2}\right)$ do not involve an improvement in the depth resolution. This range of irradiance can be obtained by working at WDs from -750 to $-2500 \mu \mathrm{m}$ and from +1500 to $+3000 \mu \mathrm{m}$ (Fig. 10). However, as was mentioned above, the shielding by the secondary plasma, which can occur at WD $<0 \mu \mathrm{m}$, decreases the efficiency of material removal, can affect particles as they escape from the crater and can even contribute to the ablation process itself. Consequently, working by focusing at a position above the sample surface is not appropriate for in-depth profile

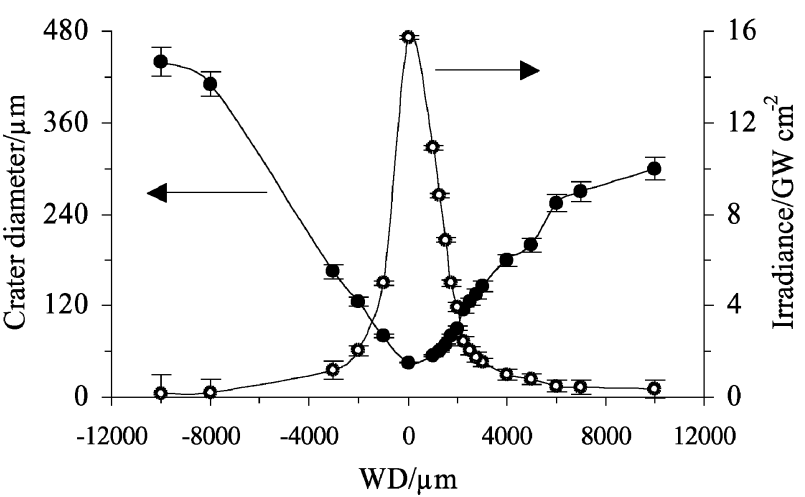

Fig. 10 Influence of WD on crater diameter and irradiance. Sample $205 \mu \mathrm{m}$ nominal thickness copper coating on steel; number of laser pulses: 100; laser pulse energy: $2 \mathrm{~mJ}$; and pulse repetition rate: $1 \mathrm{~Hz}$.

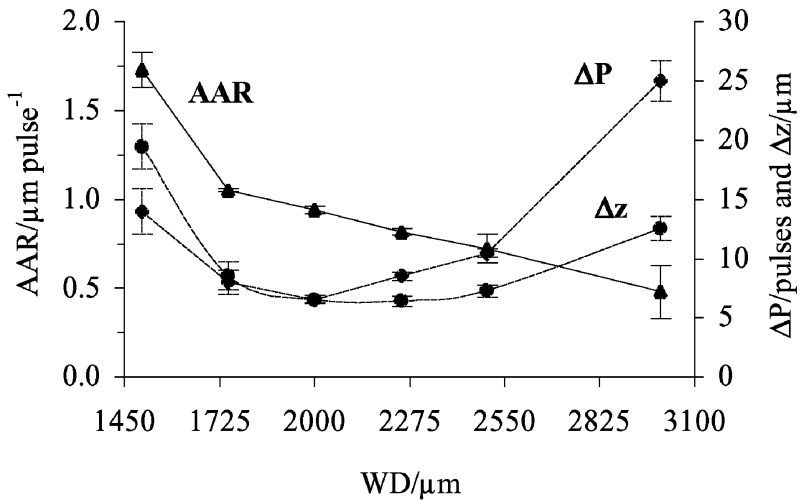

Fig. 11 Influence of WD on AAR, $\Delta P$ and $\Delta z$. Sample: $40 \mu \mathrm{m}$ nominal thickness copper coating on steel; laser pulse energy: $2 \mathrm{~mJ}$; and pulse repetition rate: $1 \mathrm{~Hz}$. 


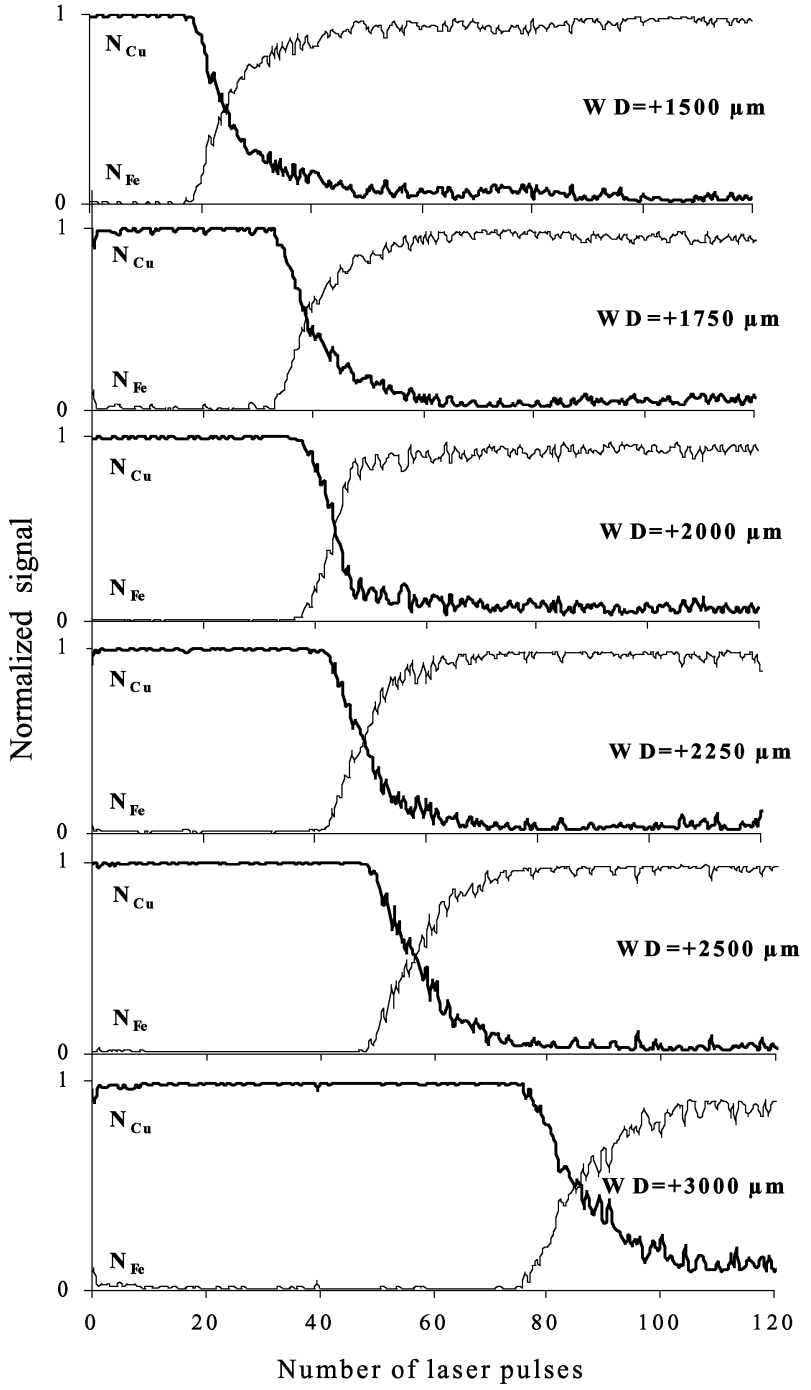

Fig. 12 Normalized in-depth profiles obtained by ablating the $40 \mu \mathrm{m}$ nominal thickness copper coating on steel sample at different WDs. Laser pulse energy: $2 \mathrm{~mJ}$; and pulse repetition rate: $1 \mathrm{~Hz}$.

analysis. Because of this, the influence of focalization on depth resolution has been investigated only in the range of WD from $+3000 \mu \mathrm{m}\left(I \approx 1.5 \mathrm{GW} \mathrm{cm}^{-2}\right)$ to $+1500 \mu \mathrm{m}\left(I \approx 6.9 \mathrm{GW} \mathrm{cm}^{-2}\right)$. In particular, the experiments were conducted for WD values of $+1500,+1750,+2000,+2250,+2500$ and $+3000 \mu \mathrm{m}$ on the 40 $\mu \mathrm{m}$ nominal thickness copper coating on steel sample by using a laser pulse energy of $2 \mathrm{~mJ}$. The AAR, $\Delta P$ and $\Delta z$ values calculated for each WD are depicted in Fig. 11. The depth profiles of normalized signals from which those values have been obtained by using eqns. (1) and (2) are shown in Fig. 12.

As can be observed in Fig. 11, AAR values decrease highly (from 1.73 to $0.48 \mu \mathrm{m}$ pulse ${ }^{-1}$, i.e., by a factor of 3.6) when WD varies from +1500 to $+3000 \mu \mathrm{m}$, that is, when the irradiance decreases. Fig. 12 illustrates the high increase of $P_{50}$ values in that range of WD, which explains the decrease of AAR values [eqn. (1)].

On the contrary, $\Delta P$ varies slightly (only 7 pulses) between +1500 and $+2500 \mu \mathrm{m}$ of WD, that is, the broadening of signals at coating/substrate interface is quite similar, as can be observed in Fig. 12. However, this parameter increases highly (from 10 to 25 pulses) when WD varies from +2500 to +3000 $\mu \mathrm{m}$. This higher $\Delta P$ value obtained at $\mathrm{WD}=+3000 \mu \mathrm{m}$ can be attributed to the low irradiance $\left(1.5 \mathrm{GW} \mathrm{cm}^{-2}\right)$ corresponding to these defocusing conditions.

The behaviour of $\Delta z$ is analogous to that of $\Delta P$, with a highest $\Delta z$ value of $20 \mu \mathrm{m}$ at $\mathrm{WD}=+1500 \mu \mathrm{m}$. This deteriora-

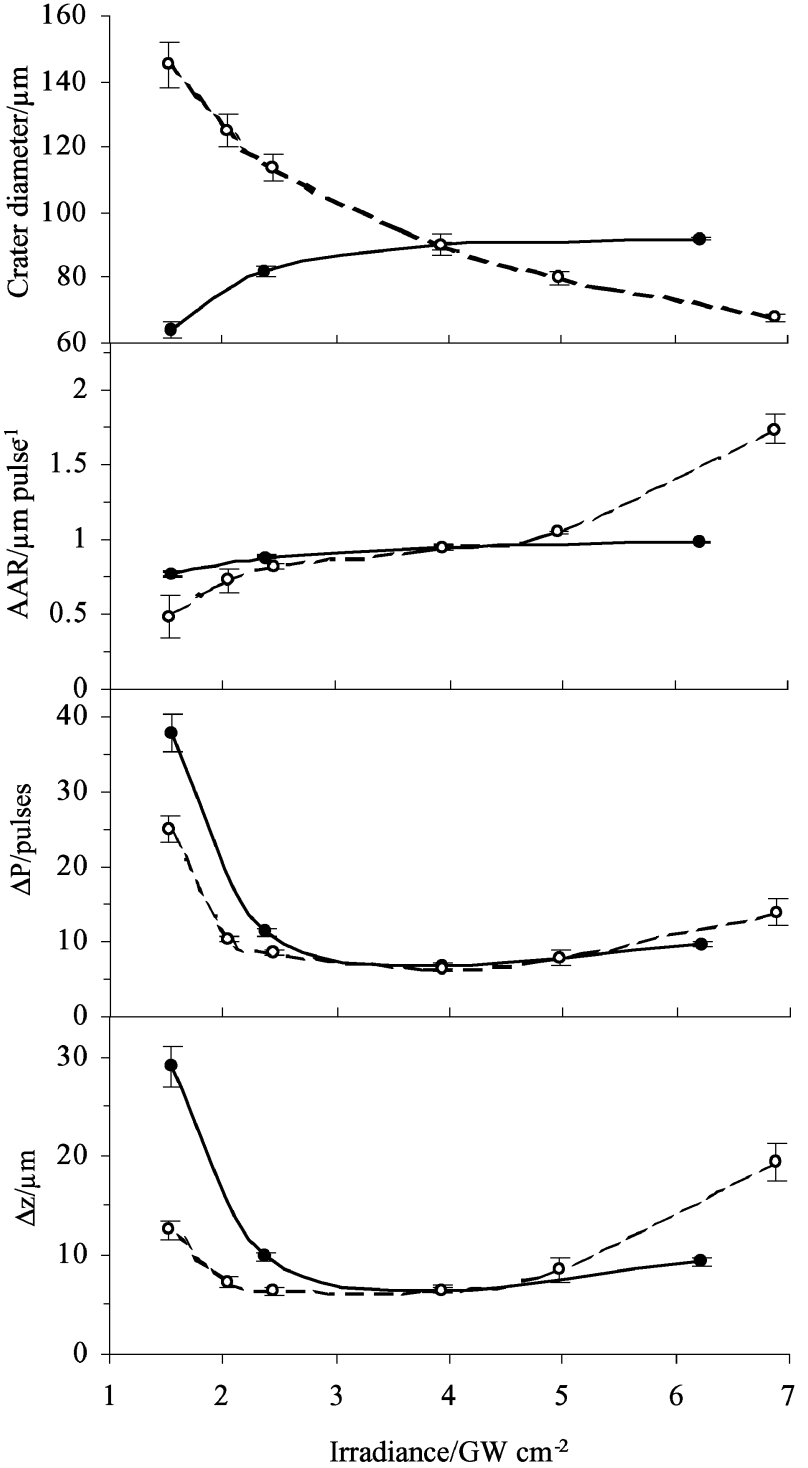

Fig. 13 Influence of irradiance obtained by changing either the laser pulse energy (filled symbols) or the WD (open symbols) on crater diameter, AAR, $\Delta P$ and $\Delta z$. Data obtained from Figs. 5, 8, 10 and 11.

tion of the depth resolution can be explained by the high AAR value at this $\mathrm{WD}$, due probably to the formation of a crater with a low diameter (Fig. 10). The $\Delta z$ values obtained for WDs between +1750 and $+2500 \mu \mathrm{m}$ are very similar. The higher $\Delta z$ value at $\mathrm{WD}=+3000 \mu \mathrm{m}$ is due to the high $\Delta P$ value at this WD. Therefore, both AAR and $\Delta P$ influence the depth resolution when WD is varied. The best depth resolution $(\Delta z=6.4$ $\mu \mathrm{m})$, with the lowest RSD value $(6 \%)$, has been obtained for $\mathrm{WD}=+2250 \mu \mathrm{m}$ (corresponding to an irradiance of $2.5 \mathrm{GW}$ $\mathrm{cm}^{-2}$, equivalent to about 8 times the ablation threshold irradiance). This WD was used for all further experiments.

For comparative purpose, the variation of crater diameter, AAR, $\Delta P$ and $\Delta z$ with the irradiance obtained by changing either the laser pulse energy or the WD is depicted in Fig. 13 from data presented in Figs. 5, 8, 10 and 11. As can be observed, at moderate irradiance levels (between 2.5 and 5 GW cm ${ }^{-2}$, i.e., between 8 and 16 times the $I_{\mathrm{th}}$ ), the behaviour of AAR, $\Delta P$ and $\Delta z$ parameters is quite similar. In addition, the best depth resolution is attained in this irradiance range. At lower irradiances (below $2.5 \mathrm{GW} \mathrm{cm}^{-2}$, i.e., below 8 times the $\left.I_{\text {th }}\right)$, AAR, $\Delta P$ and $\Delta z$ values are lower for irradiances obtained by changing the $\mathrm{WD}$, due to the larger diameter of the craters. The low ablation efficiency is the responsible for the higher $\Delta P$ and $\Delta z$ values. Contrarily, at higher irradiances (above $5 \mathrm{GW}$ 


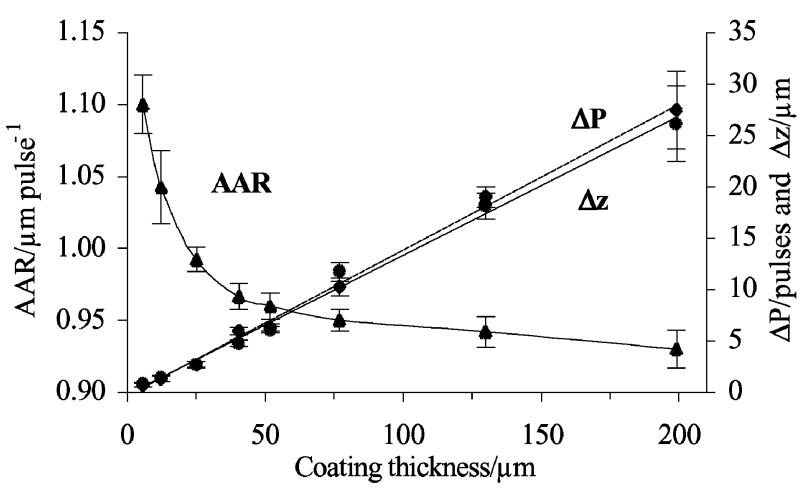

Fig. 14 Influence of copper coating thickness (from 5.9 to $199 \mu \mathrm{m}$ ) on AAR, $\Delta P$ and $\Delta z$. Laser pulse energy: $2 \mathrm{~mJ}$; pulse repetition rate: $1 \mathrm{~Hz}$; and WD: $+2250 \mu \mathrm{m}$.

$\mathrm{cm}^{-2}$, i.e., above 16 times the $\left.I_{\mathrm{th}}\right), \mathrm{AAR}, \Delta P$ and $\Delta z$ values are higher for irradiances obtained by changing the WD, which can be attributed to the formation of craters with lower diameters.

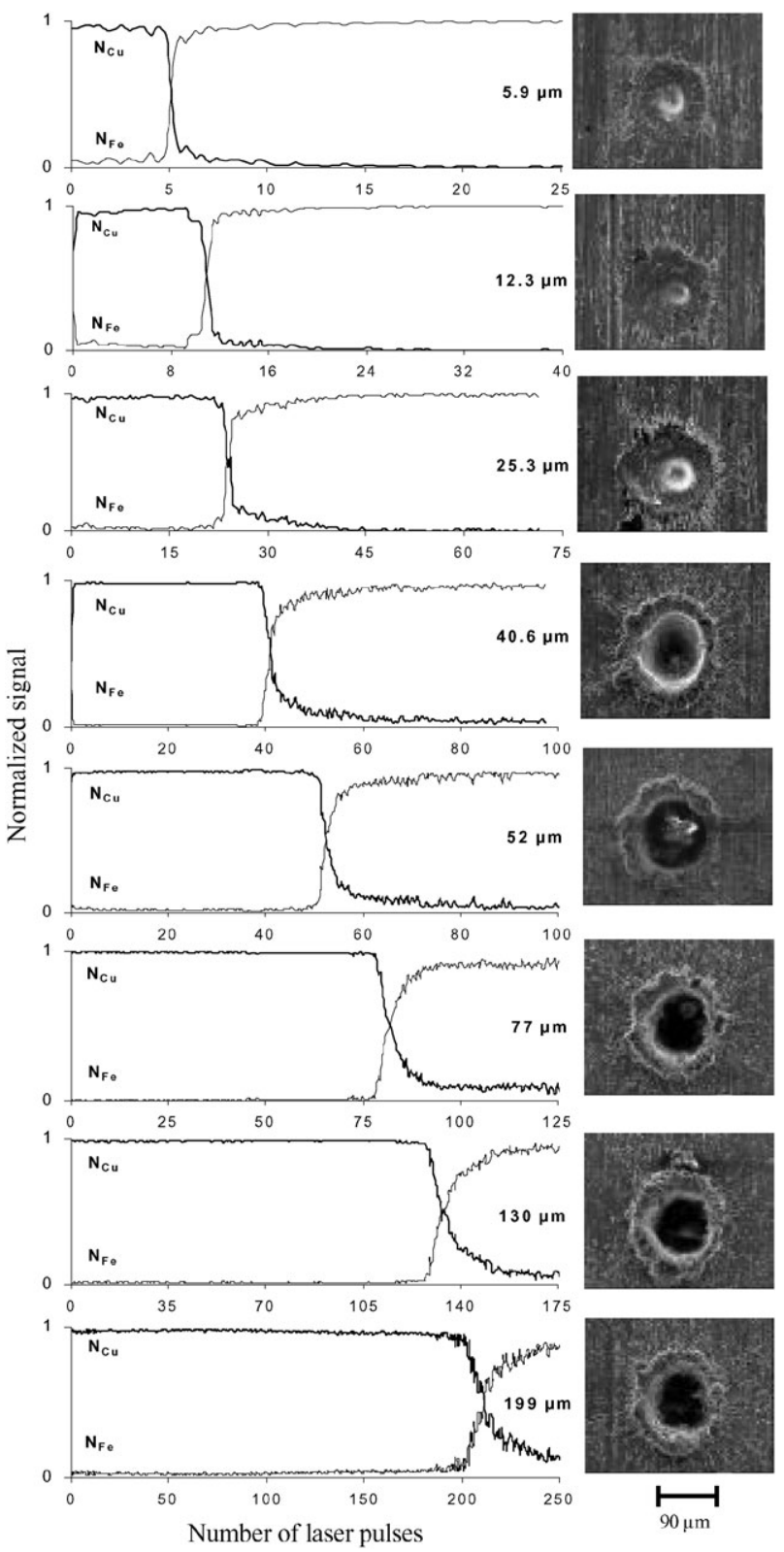

Fig. 15 Normalized in-depth profiles obtained by ablating the eight copper coating on steel samples of different coating thicknesses (from 5.9 to $199 \mu \mathrm{m}$ ) and SEM images of the obtained craters. Laser pulse energy: $2 \mathrm{~mJ}$; pulse repetition rate: $1 \mathrm{~Hz}$; and $\mathrm{WD}:+2250 \mu \mathrm{m}$.

\section{Influence of coating thickness on depth resolution}

The effect of coating thickness on depth resolution has been studied for the eight samples of different thicknesses in Table 2. Optimal conditions for laser pulse energy and working distance $\left(E=2 \mathrm{~mJ}\right.$ pulse $\left.{ }^{-1}, \mathrm{WD}=+2250 \mu \mathrm{m}\right)$, as well as the minimum pulse repetition rate $(1 \mathrm{~Hz})$, were used. The AAR, $\Delta P$ and $\Delta z$ values calculated for each sample are depicted in Fig. 14. The depth profiles of normalized signals from which those values have been obtained by using the eqns. (1) and (2) are plotted in Fig. 15, where the craters obtained for each sample are also shown. As observed in Fig. 14, AAR values decrease very slightly (from 1.10 to $0.97 \mu \mathrm{m}$ pulse ${ }^{-1}$ ) when the coating thickness increases from 6 to $40 \mu \mathrm{m}$, remaining nearly constant for coating thickness higher than $40 \mu \mathrm{m}$. The higher AAR values associated with the thinner coatings can be explained, according to Tokarev et al., ${ }^{43}$ by the three-dimensional plasma expansion that takes place on the surface and in the shallow craters, which implies a more significant material removal. For thicker coatings, the plasma expansion inside the deep crater becomes one-dimensional, and the laser beam attenuation provokes a little lowering of the AAR. However, $\Delta P$ and $\Delta z$ values increase linearly with coating thickness. The $\Delta z$ values lie between $0.76 \mu \mathrm{m}$ for the thinnest coating and $26.1 \mu \mathrm{m}$ for the thickest one. In other words, for the eight samples studied, $\Delta z$ is about 7-9 times lower than the corresponding thickness value. Taking into account that the variation of AAR with the coating thickness is very low, it can be stated that $\Delta P$, i.e., the broadening of signals at the coating/substrate interface, is the most important factor influencing the depth resolution. From Fig. 15 it is evident that it is possible to obtain a description of the element composition of both coating and substrate in copper-coated steel samples for coating thicknesses in the range from 6 to $200 \mu \mathrm{m}$.

\section{Conclusions}

It has been proved that a highly focused (Gaussian) nanosecond UV (266 nm) Nd:YAG laser ablation system coupled to an inductively coupled plasma quadrupole mass spectrometer is an appropriate technique to perform depth profile analysis of copper coating on steel samples. However, the measured coating/substrate interface is truly broader than the original indepth distribution of composition, which can be a function of the ablation process (material removal phenomena controlled by thermally based processes in the interaction of nanosecond lasers with metals) and cone-shaped crater development (modification and mixing of different depth layers along the crater walls between shallow and deep levels). An estimation of this broadening has been performed by determining the depth resolution, which permitted us to optimize the ablation conditions, leading to the best in-depth profiles. $\Delta z$ strongly depends on irradiance, as well as on the coating thickness. The best depth resolution has been attained at moderate irradiance, whereas a linear dependence of depth resolution with coating thickness has been found.

At fixed WD, $\Delta P$ is the more important factor influencing the depth resolution when the laser pulse energy is varied, whereas at fixed laser pulse energy, depth resolution depends on both AAR and $\Delta P$ when focusing conditions (and, consequently, the crater diameter) are changed. At fixed laser energy and $\mathrm{WD}, \Delta P$ is the factor controlling the depth resolution when the coating thickness is varied.

For the eight studied samples the ablation rate is approximately $1 \mu \mathrm{m}$ per pulse and $\Delta z$ is about 7-9 times lower than the corresponding thickness value. A description of the element composition of both coating and substrate, for coating thicknesses ranging from 6 to $200 \mu \mathrm{m}$, can be obtained.

The capability of LA coupled to ICP-MS (or ICP-OES) to perform depth profile analysis of metallic coated samples 
would be significantly improved by the use of homogenized laser beams and/or sub-nanosecond pulse width lasers.

\section{Acknowledgements}

This work was carried out with financial support from the European Community for Steel and Carbon (ECSC) under Project PR 4388 7210/297 and from the Comisión Interministerial de Ciencia y Tecnología (CICYT) of Spain under Project MAT2001-4588-E.

\section{References}

1 L. Moenke-Blankenburg, Spectrochim. Acta Rev., 1993, 15, 1-37.

2 R. E. Russo, Appl. Spectrosc., 1995, 49, 14A-28A.

3 S. F. Durrant, J. Anal. At. Spectrom., 1999, 14, 1385-1403.

4 J. D. Winefordner, I. B. Gornushkin, D. Pappas, O. I. Matveev and B. W. Smith, J. Anal. At. Spectrom., 2000, 15, 1161-1189.

5 D. Günther, I. Horn and B. Hattendorf, Fresenius' J. Anal. Chem., 2000, 368, 4-14.

6 R. E. Russo, X. Mao, H. Liu, J. Gonzalez and S. S. Mao, Talanta, 2002, 57, 425-451.

7 D. R. Anderson, C. W. McLeod, T. English and A. T. Smith, Appl. Spectrosc., 1995, 49, 691-701.

8 C. C. García, M. Corral, J. M. Vadillo and J. J. Laserna, Appl. Spectrosc., 2000, 54, 1027-1031.

9 J. M. Vadillo, J. M. F. Romero, C. Rodríguez and J. J. Laserna, Surf. Interface Anal., 1998, 26, 995-1000.

10 J. M. Vadillo, C. C. García, S. Palanco and J. J. Laserna, J. Anal. At. Spectrom., 1998, 13, 793-797.

11 J. M. Vadillo and J. J. Laserna, J. Anal. At. Spectrom., 1997, 12, $859-862$.

12 L. St-Onge and M. Sabsabi, Spectrochim. Acta, Part B, 2000, 55, 299-308.

13 C. C. García, J. M. Vadillo, S. Palanco, J. Ruiz and J. J. Laserna, Spectrochim. Acta, Part B, 2001, 56, 923-931.

14 M. P. Mateo, J. M. Vadillo and J. J. Laserna, J. Anal. At Spectrom., 2001, 16, 1317-1321.

15 M. P. Mateo, L. M. Cabalín and J. J. Laserna, Appl. Opt., 2003, 42, 6057-6062

16 M. Hidalgo, F. Martín and J. J. Laserna, Anal. Chem., 1996, 68 1095-1100

17 V. Margetic, M. Bolshov, A. Stockhaus, K. Niemax and R. Hergenröder, J. Anal. At. Spectrom., 2001, 16, 616-621.

18 V. Margetic, K. Niemax and R. Hergenröder, Anal. Chem., 2003, 75, 3435-3439.
19 V. Kanicky, V. Otruba and J. M. Mermet, Fresenius' J. Anal. Chem., 2000, 366, 228-233.

20 V. Kanicky, I. Novotny, J. Musil and J. M. Mermet, Appl. Spectrosc., 1997, 51, 1042-1046.

21 D. Bleiner, P. Lienemann, A. Ulrich, H. Vonmont and A. Wichser, J. Anal. At. Spectrom., 2003, 18, 1146-1153.

22 A. Plotnikov, C. Vogt, V. Hoffmann, C. Täschner and K. Wetzig, J. Anal. At. Spectrom., 2001, 16, 1290-1295.

23 D. Bleiner, A. Plotnikov, C. Vogt, K. Wetzig and D. Günther, Fresenius' J. Anal. Chem., 2000, 368, 221-226.

24 V. Kanicky, H. R. Kuhn and D. Guenther, Anal. Bioanal. Chem., 2004, 380, 218-226.

25 A. J. G. Mank and P. R. D. Mason, J. Anal. At. Spectrom., 1999, 14, 1143-1153.

26 P. R. D. Mason and A. J. G. Mank, J. Anal. At. Spectrom., 2001, 16, 1381-1388

27 V. Kanicky, V. Otruba and J. M. Mermet, Spectrochim. Acta, Part $B, 2000,55,575-586$.

28 B. N. Chichkov, C. Momma, S. Nolte, F. Alvensleben and A. Tünnermann, Appl. Phys. A, 1996, 63, 109-115.

29 A. Luft, U. Franz, A. Emsermann and J. Kaspar, Appl. Phys. A, 1996, 63, 93-101.

30 C. Körner, R. Mayerhofer, M. Hartmann and H. W. Bergmann, Appl. Phys. A, 1996, 63, 123-131.

31 J. Jandeleit, G. Urbasch, H. D. Hoffmann, H. G. Treusch and E. W. Kreutz, Appl. Phys. A, 1996, 63, 117-121.

32 L. St-Onge, J. Anal. At. Spectrom., 2002, 17, 1083-1089.

33 S. Hofmann, Surf. Interface Anal., 1999, 27, 825-834.

34 P. Rudolph, J. Bonse, J. Krüger and W. Kautek, Appl. Phys. A, 1999, 69, S763-S766.

35 S. Martin, A. Hertwig, M. Lenzner, J. Krüger and W. Kautek, Appl. Phys. A, 2003, 77, 883-884.

36 Y. Dong and P. Molian, Appl. Phys. A, 2003, 77, 839846.

37 J. Bonse, P. Rudolph, J. Krüger, S. Baudach and W. Kautek, Appl. Surf. Sci., 2000, 154-155, 659-663.

38 T. Li, Q. Lou, J. Dong, Y. Wei and J. Liu, Appl. Surf. Sci., 2001, 172, 356-365.

39 L. M. Cabalín and J. J. Laserna, Spectrochim. Acta, Part B, 1998, 53, 723-730.

40 J. M. Vadillo, J. M. F. Romero, C. Rodríguez and J. J. Laserna, Surf. Interface Anal., 1999, 27, 1009-1015.

41 X. Mao and R. E. Russo, Appl. Phys. A, 1997, 64, 1-6.

42 L. M. Cabalín, D. Romero, J. M. Baena and J. J. Laserna, Fresenius' J. Anal. Chem., 1999, 365, 404- 408.

43 V. N. Tokarev, J. Lopez, S. Lazare and F. Weisbuch, Appl. Phys. A, 2003, 76, 385-396. 